\title{
BRAF Expression in Keratoacanthoma
}

\author{
Sevda Önder ${ }^{1}$, Havva Erdem ${ }^{2}$, Mürüvvet Akçay Çelik ${ }^{2}$ \\ ${ }^{1}$ Ordu University, Faculty of Medicine, Department of Dermatology, Ordu, Turkey \\ ${ }^{2}$ Ordu University, Faculty of Medicine, Department of Pathology, Ordu, Turkey
}

\begin{abstract}
Received: 28 February 2019, Accepted 10 May 2019, Published online: 31 December 2019
\end{abstract}
(C) Ordu University Institute of Health Sciences, Turkey, 2019

\begin{abstract}
Objective: Mutations in genes encoding proteins along the RAS-RAF-MEK-ERK pathway have been detected in a variety of tumor entities, including malignant melanoma, thyroid, colon, over carcinomas and some sarcomas. The increased activity of BRAF V600E leads to downward signalization activation via mitogen-activated protein kinase (MAPK), which plays an important role as cell growth, differentiation and survival regulator. Latest data show BRAF undergoes mutation in nearly $7 \%$ of cancers and this situation makes BRAF another important oncogene in this pathway. We aimed to evaluate the relationship between keratacanthoma and BRAF expression.

Methods: 28 cases of keratocanthomas were included in this study. Sections were taken from the selected blocks with a thickness of 3 microns with poly-lysine coating. BRAF antibody was applied to the tissues. The obtained preparations were evaluated by light microscopy. It was rated according to the degree of staining in epidermis.

Results: Areas showing cytoplasmic staining with BRAF were evaluated in sections. It was observed that there was no staining in the keratocanthomas, and staining in sebaceous glands and sweat glands in peripheral basal cells. It was also noted that the sweat glands had more stain than the sebaceous glands. The cases included 18 males and 10 females with ages varying from 33 to 85 years. The duration of the lesions was between one month and one year. Lesion dimensions varied from 5 to $70 \mathrm{~mm}$, with mean size of $21 \mathrm{~mm}$. There were 14 cases (50\%) with head and neck localization, and 14 cases (50\%) with localization other than the head and neck.
\end{abstract}

Conclusion: As a result, it has been concluded that BRAF mutation may not be involved in keratoacanthoma. Key words: BRAF; keratoacanthoma; expression.

Suggested Citation: Onder S, Erdem H, Akcay Celik M. BRAF expression in keratoacanthoma. Middle Black Sea Journal of Health Science, 2019; 5(3): 162-167

Address for correspondence/reprints:

\section{Sevda Önder}

Telephone number: +90 (452) 2265200

E-mail: drsevdaonder@gmail.com

DOI: $10.19127 / \mathrm{mbsjohs} .533416$

\section{Introduction}

The basis of the mitogen-activated protein kinase (MAPK) pathway is a signal pathway involving RAS, RAF, mitogen and extracellularregulated protein kinase kinase (MEK) and extracellular signal regulating kinase (ERK) and is active in many tumors due to mutations in the RAS or RAF families. Discovery of mutations in one of the RAF kinase family members of BRAF (v-raf murine sarcoma viral oncogene homolog B) contributed greatly to advances in melanoma research and it is generally associated with earlystage melanoma (Abildgaard et al., 2015). 
Additionally, BRAF mutations are observed with high frequency in melanocytic nevi (Davies et al., 2002; Pollock et al., 2003; Kumar et al., 2004). This clearly shows the role of BRAF in early melanomagenesis (Tsao et al., 2012). Latest data show BRAF undergoes mutation in nearly $7 \%$ of cancers and this situation makes BRAF another important oncogene in this pathway (Garnett et al., 2004).

The highest incidence of BRAF mutations is in malignant melanoma (27-79\%), papillary thyroid cancer $(36-53 \%)$, colorectal cancer $(5-22 \%)$ and serous ovarian cancer (30\%). However, low incidence mutations (1-3\%) may occur in a variety of other cancers (Davies et al., 2002; Garnett et al., 2004).

Keratoacanthoma (KA) is a dome-shaped lesion filled with keratin originating in hair follicles. It is commonly observed in humans and the cause of the tumor is not fully known. However, currently the histopathologic diagnosis criteria, prognosis and treatment protocols are still controversial. Names used for KA include molluscum sebaceum, pseudotumor, regressing tumor and self-healing squamous cell carcinoma (SCC) (Kwiek et al., 2016).

Histopathologically KA has some defined characteristics (Clausen et al., 2006). The surface epithelium at the lateral margin of the tumor appears normal; however, there is a clear angle observed between the lesion and the upper epithelium at the lip section of the crater in the center of the lesion. The crater is filled with keratin and the epithelial cells at the base of the lesion proliferate toward the bottom and generally induce a significant chronic inflammatory response. Dyskeratosis may cause confusion with well-differentiated SCC (Chauhan et al., 2011). The architecture of the tumor is more important than cytologic features for diagnostic procedures (Chauhan et al., 2011) because it may show microscopic features of SCC such as lesion infiltration and cellular atypia (Neville et al., 2009). The most common concern remains the boundary between malignancy and benignity of the tumor. This indecision is difficult for both clinicians and researchers but may be key to understanding the regression of this tumor (Kwiek et al., 2016).

In this study we aimed to investigate the BRAF expression in KA cases.

\section{Methods}

Twenty-eight cases of keratoacanthoma were included in this study. Hematoxylin-eosin slides of tissue samples were re-examined, and appropriate paraffin blocks were selected. Sections were taken from the selected blocks with poly-lysine slides 3 microns thick. BRAF antibody was applied to the tissues. Immunohistochemical staining was performed by deparaffinization, dehydration and incubation in buffered citrate (1/200 dilution). Staining was performed using Ultra Vision Polyvalent, HRP-AEC kit (Neomarkers-Biogen, Lab Vision Corp. USA). The obtained slides were evaluated using light microscopy. They were graded according to the degree of staining in the epidermis (Figure 1-3). Cytoplasmic positive areas with BRAF were evaluated in the sections (Adackapara et al., 2013).

Descriptive analysis was used for statistical analysis in this study.

The trial was performed in accordance with clinical practice and the Helsinki Declaration. Approval was granted by the local ethics committee of Ordu University (2018-142).

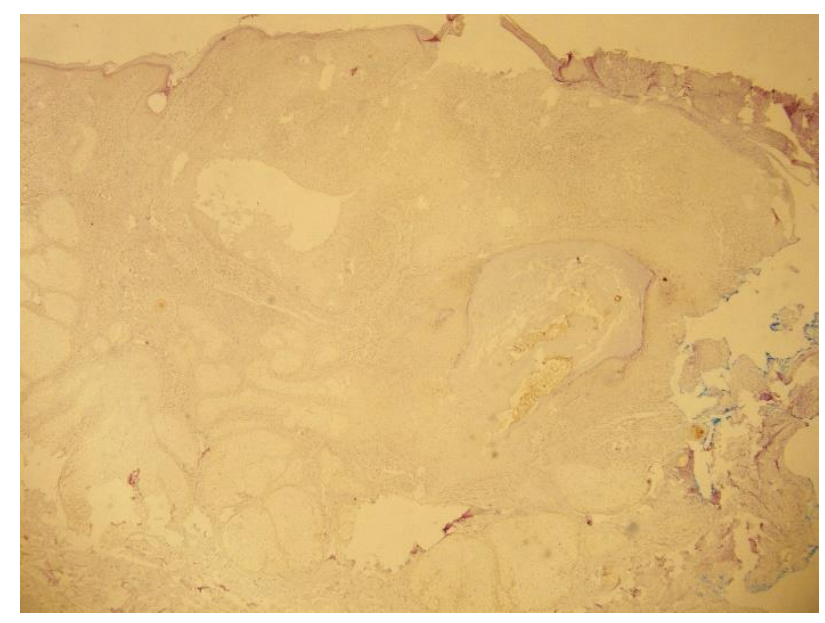

Figure 1. Loss of BRAF expression in crater cells (x40). 


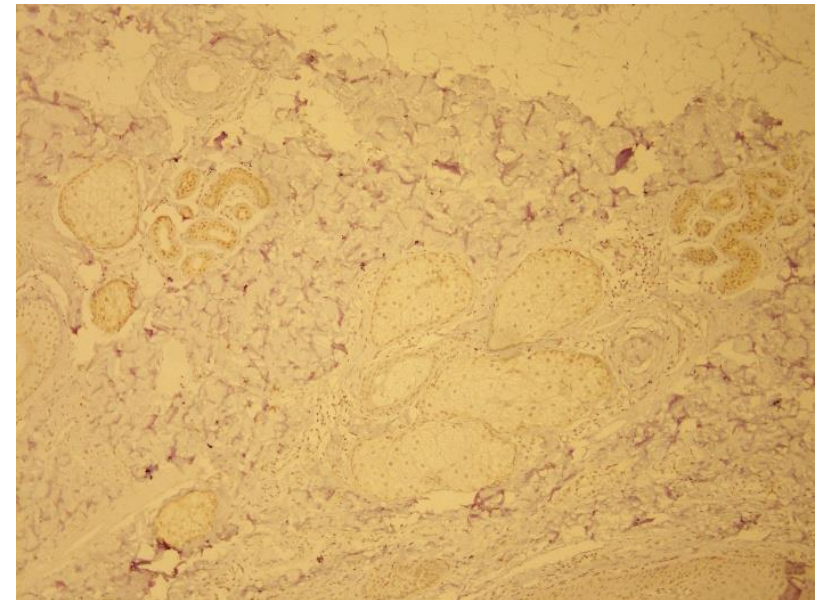

Figure 2. BRAF expression in sweat glands and sebaceous glands (x100).

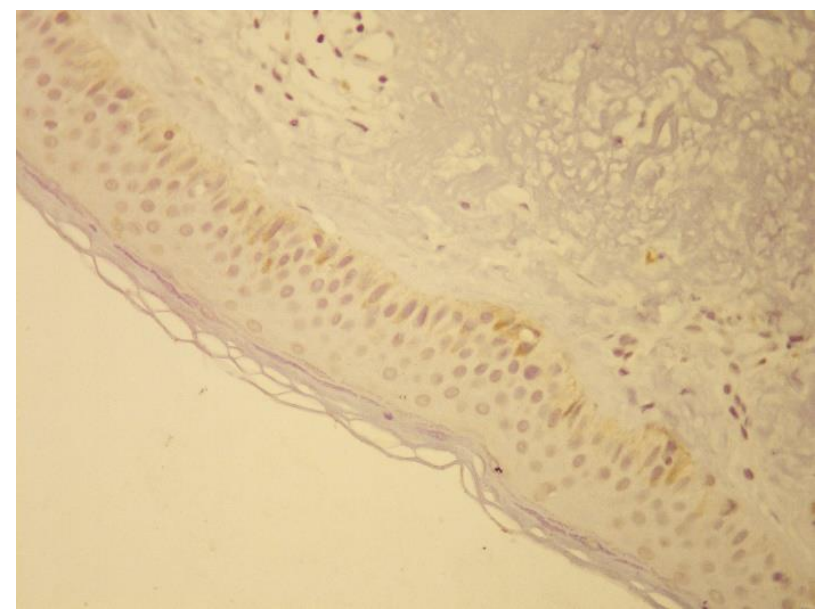

Figure 3. BRAF expression in basal cells outside crater $(\mathrm{x} 400)$.

\section{Results}

A total of 28 cases with KA were evaluated. Positive areas with BRAF were evaluated in the sections. It was observed that there was no staining in the keratinocyte, and there was staining in sebaceous glands and sweat glands and peripheral basal cells outside the crater. It was also noted that the sweat glands had more stain than the sebaceous glands. The cases included 18 males and 10 females with ages varying from 33 to 85 years (mean 50). The duration of the lesions was between one month and one year. Lesion dimensions varied from 5 to 70 $\mathrm{mm}$, with mean size of $21 \mathrm{~mm}$. There were 14 cases $(50 \%)$ with head and neck localization, and 14 cases (50\%) with localization other than the head and neck.

\section{Discussion}

KA is a benign keratinocytic tumor sourced in hair follicles (Neville et al., 2009). It is encountered as clinically sporadic, solitary lesion showing rapid growth over four to five weeks and then resolving after six months (Aksoy B et al., 2017). Numerous studies have investigated the differences between KA and SCC in terms of cellular proliferation, apoptosis and cell cycle, and histomorphological regulation of molecules (Tan et al., 2013). In the literature there are contradictory ideas related to the nature of KA. Just as KAs are accepted as a subgroup of SCC or a precancerous SCC lesion, some authors accept them as benign lesions completely different from SCC (Aksoy et al., 2017). Though KAs mostly regress spontaneously, some immunosuppressive patients with KA were reported to develop metastasis. This led to debate about whether KA is a different entity or a variant of cutaneous SCC (Putti et al., 2004). Unfortunately, there are no clinical signs to differentiate KA from SCC with high specificity and sensitivity (Aksoy et al., 2017).

Among etiologic factors causing KAs are immunosuppression, ultraviolet radiation, chemical factors, genetic factors, BRAF inhibitors (vemurafenib, dabrafenib), hedgehog pathway inhibitors (vismodegib) and foreign material like tattoos or fillers (Aksoy et al., 2017; Tan et al., 2013; Putti et al., 2004; Hodak et al., 1993). Since the beginning of use of BRAF inhibitor treatment for melanoma and hedgehog pathway inhibitor treatment for advanced basal cell carcinoma, the incidence of KA has increased (Bell et al., 2015; Sarah et al., 2015). BRAF inhibitors are shown to lengthen survival in stage 4 metastatic melanoma patients with BRAF V600E mutation. However, development of KA, verrucous keratosis and cutaneous SCC is a disadvantage of the medication (Anforth et al., 2012).

Recent evidence in vitro and in vivo suggests that selective BRAF inhibitors can induce activation of downstream elements of the MAPK pathway in BRAF wild-type cancer cells (Hatzivassiliou et al., 2010; Heidorn et al., 2010; Poulikakos et al., 2010). A recent study showed BRAF inhibitors affect genetically abnormal keratinocytes causing formation of de novo lesions (Alloo et al., 2012).

In a study, data indicates that RAS mutations are present in approximately $60 \%$ of cases treated with BRAF inhibitors. The researchers reported mutations present may cause tendency for SCC and KA development (Fei et al., 2012). In this study, 
absence of BRAF supports the presence of RAS mutation in KA.

There are many studies examining the relationship of squamoproliferative lesions due to BRAF inhibitors such as KA, verrucous papilloma (VP), SCC. In a study the authors evaluated both the MAPK pathway and the presence of (Human Papilloma Viruses) HPV and other polyomaviruses (HPyV), especially Merkel cell polyomavirus $(\mathrm{MCPyV})$, in a group of BRAF inhibitor induced verrucous papillomas (VP), keratoacanthomas and squamous cell carcinomas. They detected HPV only in 2 VPs and they didn't show any relation between KAs and HPV (Frouin et al., 2014). In an another study, Schrama et al detected HPV in 14 cSCC, 3 KA and one acanthoma samples and all were HPV positive (Schrama et al., 2014). The results are controversial as to whether or not HPV has an effect on KA development in patients under melanoma treatment. In an another molecular study authors compare the mutational profiles of lesions after treatment with a BRAF inhibitor, with similar lesions arising sporadically. HRAS mutations were common among the BRAF inhibitor-induced lesions. So, despite similar histomorphological appearances, the underlying molecular mechanisms may be different. In addition, within the BRAF inhibitor-associated group, the lesions designated as KAs and BRAF inhibitor-associated verrucous keratoses had a similar mutational profile (mutations in PIK3CA, APC, and HRAS), which was distinct from squamous cell carcinomas (FGFR3, CDKN2A, and STK11) (Clynick et al., 2015).

The mechanism underlying SCC development in patients treated with RAF inhibitors is currently being actively researched (Hatzivassiliou et al., 2010; Heidorn et al., 2010; Poulikakos et al., 2010). A study by Arnault et al. (Arnault et al., 2012) compared normal skin biopsy samples taken from patients treated with sorafenib with skin with normal appearance taken from patients treated with placebo. They showed the histologic sections of patients treated with sorafenib had increased rates of Ki67 and phosphorylated ERK staining in keratinocytes. They suggested the MAPK signaling was actually increased in patients treated with sorafenib and this probably caused increased keratinocyte proliferation. However, paradoxical activation of MAPK signaling alone may not be sufficient to induce SCC and KA. With this aim, Oberholzer et al. (Oberholzer et al., 2012) compared patients treated with vemurafenib (30\%) and sorafenib (11\%) with a control group (3.2\%) and identified RAS activated mutations were more common in SCC and KA of treated patients. Previously existing RAS mutations in keratinocytes (probably due to sun exposure or viral infections) may be a "second hit" on the paradoxical activation pathway beginning with MAPK signaling by the RAF inhibitor, and this will be sufficient for tumor development.

In our study, expression of BRAF was not seen in the KA crater cells. Expression was seen in basal cells outside the crater of the lesions. In addition, expression of BRAF was seen in the sweat and sebaceous glands. We noted that the expression in the sweat gland was greater than in the sebaceous glands.

In a study of melanomas with anorectal location, positive BRAF expression was observed in the control group and anorectal glands. However, BRAF expression was negative in all cases of primary anorectal melanoma (Tse et al., 2016). Other published studies found that among 323 colorectal carcinoma cases with wild-type BRAF by sequence analysis, 196 cases $(61 \%)$ did not stain with the BRAF antibody (Estrella et al., 2015).

\section{Conclusion}

In this study, expression in the basal cell and gland is nonspecific. No significant staining was observed in the cases. Extensive research is needed to demonstrate the relationship between BRAF and KA. The staining of the glands is thought to be nonspecific because it was not associated with histopathology of keratoacanthoma.

Ethics Committee Approval: Ethics committee approval was received for this study from School of medicine Clinical Research Ethics Committee (2018-142) of Ordu University.

Peer-review: Externally peer-reviewed.

Author Contributions: Concept- S.Ö, H.E, DesignS.Ö, H.E., M.A.Ç., Supervision- H.E., M.A.Ç., Literature Review- S.Ö., H.E, Writing- S.Ö., M.A.Ç, Critical Review- H.E.

Conflict of Interest: No conflict of interest was declared by the author.

Financial Disclosure: The authors declared that this study hasn't received no financial support. 


\section{References}

Abildgaard C, Guldberg P. Molecular drivers of cellular metabolic reprogramming in melanoma. Trends Mol Med 2015;21:164-71.

Adackapara CA, Sholl LM, Barletta JA, Hornick JL Immunohistochemistry using the BRAF V600E mutation-specific monoclonal antibody VE1 is not a useful surrogate for genotyping in colorectal adenocarcinoma.

Histopathology. 2013 Aug;63(2):187-93.

Aksoy B, Aksoy HM, Akın O. Keratoacanthoma in an acrochordon. Turkderm-Turk Arch Dermatol Venereolgy 2017;51:24-5.

Alloo A, Garibyan L, LeBoeuf N, Lin G, Werchniak A, Hodi FS Jr, et al. Photodynamic therapy for multiple eruptive keratoacanthomas associated with vemurafenib treatment for metastatic melanoma. Arch Dermatol.2012 Mar;148(3):363-6.

Anforth R, Tembe V, Blumetti T, Fernandez-Peñas P. Mutational analysis of cutaneous squamous cell carcinomas and verrucal keratosis in patients taking BRAF inhibitors. Pigment Cell Melanoma Res. 2012;25(5):569-72.

Arnault JP, Mateus C, Escudier B, Tomasic G, Wechsler J, Hollville E, et al. Skin tumors induced by sorafenib; paradoxic RAS-RAF pathway activation and oncogenic mutations of HRAS, TP53, and TGFBR1. Clin Cancer Res. 2012 Jan 1;18(1):263-72.

Bell D, Aung P, Prieto VG, Ivan D. Next-Generation Sequencing Reveals Rare Genomic Alterations in Aggressive Digital Papillary Adenocarcinoma. Annals of Diagnostic Pathology. 2015; 19(6): 381-384.

Chauhan A, Chaudhary S, Agnihotri PG, Aadithya B. A solitary crateriform ulcer of the lower lip: a case report with review of literature. Indian $\mathbf{J}$ Dermatol. 2011; 56: 435-438.

Clausen OP, Aass HC, Beigi M, Purdie KJ, Proby $\mathrm{CM}$, Brown VL, et al. Are keratoacanthomas variants of squamous cell carcinomas? A comparison of chromosomal aberrations by comparative genomic hybridization. J Invest Dermatol. 2006; 126: 2308-2315.

Clynick B, Tabone T, Fuller K, Erber W, Meehan K, Millward M, et al. Mutational Analysis of BRAF Inhibitor-Associated Squamoproliferative Lesions.J Mol Diagn. 2015 Nov;17(6):644-51.

Davies H, Bignell GR, Cox C, Stephens P, Edkins S, Clegg S, et al. Mutations of the BRAF gene in human cancer. Nature 2002;417:949-54.
Estrella JS, Tetzlaff MT, Bassett RL Jr, Patel KP, Williams MD, Curry JL, et al. Assessment of BRAF V600E Status in Colorectal Carcinoma: Tissue-Specific Discordances between Immunohistochemistry and Sequencing. Mol Cancer Ther. 2015 Dec;14(12):2887-95.

Su F, Viros A, Milagre C, Trunzer K, Bollag G, Spleiss O, et al. RAS Mutations in Cutaneous Squamous-Cell Carcinomas in Patients Treated with BRAF Inhibitors. N Engl J Med. 2012; 366(3): 207-215.

Frouin E, Guillot B, Larrieux M, Tempier A, Boulle $\mathrm{N}$, Foulongne $\mathrm{V}$, et al. Cutaneous epithelial tumors induced by vemurafenib involve the MAPK and Pi3KCA pathways but not HPV nor HPyV viral infection. PLoS One. 2014 Oct 31;9(10):e110478.

Garnett M, Marais R. Guilty as charged: B-RAF is a human oncogene. Cancer Cell 2004;6:313-9.

Hatzivassiliou G, Song K, Yen I, Brandhuber BJ, Anderson DJ, Alvarado R, et al. RAF inhibitors prime wild-type RAF to activate the MAPK pathway and enhance growth. Nature. 2010;464 (7287): 431-435.

Heidorn SJ, Milagre C, Whittaker S, Nourry A, Niculescu-Duvas I, Dhomen N, et al. Kinasedead BRAF and oncogenic RAS cooperate to drive tumor progression through CRAF. Cell. 2010;140(2):209-221.

Hodak E, Jones RE, Ackerman AB. Solitary keratoacanthoma is a squamous cell carcinoma: three examples with metastases. Am J Dermatopathol 1993; 4:332-342.

Kumar R, Angelini S, Snellman E, Hemminki K. BRAF mutations are common somatic events in melanocytic nevi. J Invest Dermatol 2004;122:342-8.

Kwiek B, Schwartz RA. Keratoacanthoma (KA): An update and review. J Am Acad Dermatol. 2016 Jun;74(6):1220-33.

Neville BW, Damm DD, Allen CM, Bouquot JE. Oral \& Maxillofacial Pathology. 3th ed, Saunders Co: China; 2009. p. 407.

Oberholzer PA, Kee D, Dziunycz P, Sucker A, Kamsukom N, Jones R, et al. RAS mutations are associated with the development of cutaneous squamous cell tumors in patients treated with RAF inhibitors. J Clin Oncol. 2012;30:316-21.

Pollock PM, Harper UL, Hansen KS, Yudt LM, Stark M, Robbins CM, et al. High frequency of BRAF mutations in nevi. Nat Genet 2003;33:1920. 
Poulikakos PI, Zhang C, Bollag G, Shokat KM, Rosen N. RAF inhibitors transactivate RAF dimers and ERK signalling in cells with wildtype BRAF. Nature. 2010;464 (7287): 427-430.

Putti T, Teh M, Lee Y. Biological behavior of keratoacanthoma and squamous cell carcinoma: telomerase activity and $\mathrm{COX}-2$ as potential markers. Modern Pathology. 2004; 17: 468-475.

Sarah J. Welsh, Pippa G. Corrie. Management of BRAF and MEK inhibitor toxicities in patients with metastatic melanoma. Ther Adv Med Oncol. 2015; 7(2): 122-136.
Schrama D, Groesser L, Ugurel S, Hafner C, Pastrana DV, Buck CB, et al. Presence of human polyomavirus 6 in mutation-specific BRAF inhibitor-induced epithelial proliferations. JAMA Dermatol. 2014 Nov;150(11):1180-6.

Tan KB, Tan SH, Aw DC, Jaffar H, Lİm TC, Lee SJ, et al. Simulators of squamous cell carcinoma of the skin: diagnostic challenges on small biopsies and clinicopathological correlation. J Skin Cancer. 2013;2013:752864. 